\title{
Effect of Butanol Addition to Neem Biodiesel-Diesel Blend on Emission Characteristics of Diesel Engine
}

\author{
*BITRUS, R; RUFAI, IA; OGWEDA, SH \\ Department of Mechanical Engineering, Bayero University Kano, Kano State, Nigeria. \\ *Corresponding Author Email: rnbmintin@gmail.com
}

\begin{abstract}
The effect of butanol addition in biodiesel-diesel blend to ascertain the emission characteristics of diesel engine was investigated. Experiments were carried out on a four-stroke, single cylinder, air-cooled compression ignition engine. A blend of neem biodiesel $20 \%$ and diesel fuel $80 \%$ was prepared and labelled as B20. Butanol was then added to B20 blend at volume percent of 5\%,10\% and $15 \%$ which was labelled as B20Bu5, $\mathrm{B} 20 \mathrm{Bu} 10$ and $\mathrm{B} 20 \mathrm{Bu} 15$ respectively. These samples were tested on the engine at two conditions: firstly, when speed was constant (2600 rpm) with varying torque of 4, 6, 8, 10 and $11 \mathrm{Nm}$, and secondly when torque was constant (4 $\mathrm{Nm}$ ) with varying speed of 2000, 2200, 2400 and $2600 \mathrm{rpm}$. Exhaust gas analyzer was used to measure exhaust emissions such as nitric oxide (NO), carbon dioxide $\left(\mathrm{CO}_{2}\right)$, carbon monoxide $(\mathrm{CO})$ and unburnt hydrocarbon $(\mathrm{HC})$. The result shows that $\mathrm{B} 20$ blend has the highest amount of $\mathrm{NO}$ emission at all engine loads. At varying speed B20 blend was found to have $\mathrm{NO}$ emission of $303.8 \mathrm{ppm}$ on average but the addition of butanol to B20 blend significantly reduced the amount of $\mathrm{NO}$ emission by $16 \%$. NO emission reduced much with more percentage of butanol in the blend. In regards to $\mathrm{CO}_{2}$ emission, it was found that blends containing butanol emits higher amount of $\mathrm{CO}_{2}$ than $\mathrm{B} 20$ blend. However, $\mathrm{CO}_{2}$ emission decreased as percentage of butanol in the blend increase. At constant speed B20 blend increases $\mathrm{CO}$ emission more than blends containing butanol while at varying speed the result shows very insignificant difference. It was also revealed that blends containing butanol releases higher $\mathrm{HC}$ emissions than B20 blend across all engine speeds. At varying torque B20 blend emits higher HC than blends with butanol except for B20Bu15 which has $16.4 \mathrm{ppm}$ on average. A regression equation was developed in order to predict the exhaust emissions at specific engine conditions using a particular fuel blend.
\end{abstract}

\section{DOI: https://dx.doi.org/10.4314/jasem.v24i5.24}

Copyright: Copyright $(\mathrm{C} 2020$ Bitrus et al. This is an open access article distributed under the Creative Commons Attribution License (CCL), which permits unrestricted use, distribution, and reproduction in any medium, provided the original work is properly cited.

Dates: Received: 12 March 2020; Revised: 22 April 2020; Accepted: 21 May 2020

Keywords: Butanol, neem-biodiesel-diesel, emissions and predictive equation

\section{INTRODUCTION}

Energy demand and usage all over the globe has significantly increased due to modernization and industrialization. Diesel engines are part of this industrialization as a result of their high torque, durability, high fuel conversion efficiencies and fuel economy. Since petroleum products are nonrenewable energy sources, their day to day consumption leads to the depletion of these products. The resulting emissions from the combustion of diesel fuel have great adverse effects to both human health and also the environment. The fore mention problems prompted researchers to finding alternative fuel sources that are renewable and have the potential of reducing global warming. Biodiesel has received considerable attention in recent years as alternative fuel for diesel engine. It is renewable, nontoxic and readily biodegradable, is free of sulfur and aromatic compounds, and possesses a higher cetane number, higher flash point and better lubricity performance (Zhang and Balasubramanian, 2014). Many studies have been conducted on the use of these biodiesel blends in diesel engines to achieve both the environmental and energy benefits. The use of dieselbiodiesel blends has shown a significant reduction in emissions of various regulated pollutants such as particulate matter (PM), unburnt hydrocarbon (HC), carbon monoxide (CO) from diesel engine except for the oxides of nitrogen (NOx) emissions which increased (Mehta et al., 2010). Alcohols like ethanol have been used most often as additives in diesel fuel (due to their oxygenated nature) in order to enhance combustion efficiency of diesel engines. The major drawback in ethanol-diesel blends is that ethanol is immiscible in diesel over a wide range of temperatures (Lapuerta et al., 2009), while butanol is completely miscible in diesel and biodiesel blends. The use of biodiesel blends in diesel engine has led to lower emissions of PM, $\mathrm{HC}$ and $\mathrm{CO}$, as well as increase in NOx emissions as compared to conventional diesel fuel (Mehta et al., 2010). Therefore, it is necessary to reduce these emissions to a moderate and acceptable level. The aim of this research work is to evaluate the effect of the addition of butanol to biodiesel-diesel blend on exhaust emissions of diesel engine and use 
regression analysis to develop predictive equations for the emissions.

\section{MATERIALS AND METHODS}

Engine Setup: The engine was mounted on an engine test bed and coupled to a hydraulic brake dynamometer which has transducers measuring the engine torque and displaying it on the instrumentation unit. The engine was connected to TechQuipment TD 114 instrumentation unit which allows the measurements of fuel and air consumption rates. NHA-506EN Automotive Emissions Analyzer probe was inserted into the exhaust of the engine to measure the emission gases. The engine specification is listed in Table 1.

\begin{tabular}{|c|c|}
\hline Engine Model & $165 \mathrm{~F}$ \\
\hline Type & $\begin{array}{l}\text { Horizontal single } \\
\text { cylinder 4-stroke, } \\
\text { air cooled }\end{array}$ \\
\hline Bore (mm) & 65 \\
\hline Stroke (mm) & 70 \\
\hline Maximum Torque (Nm) & 12 \\
\hline Rated Speed (rpm) & 2600 \\
\hline Rated Power (kW) & 2.43 \\
\hline Compression ratio & $20.5-22$ \\
\hline Specific Fuel Consumption (g/kwh) & $\leq 284.2$ \\
\hline
\end{tabular}

Experimentation: The fuel blends were prepared as follows: $80 \%$ diesel and $20 \%$ biodiesel were blended and denoted as B20, and then butanol was added to $\mathrm{B} 20$ blend in $5 \%, 10 \%$ and $15 \%$ by volume and were labelled as B20Bu5, B20Bu10 and B20Bu15 respectively. The procedures below were followed in order to obtain all experimental data. (i) Diesel fuel was poured into the engine fuel tank, then the engine was started and allowed to run for 3 minutes to get stabilized. (ii) The engine was then set to run at constant speed of $2600 \mathrm{rpm}$ with a load of $4 \mathrm{Nm}$. (iii) As the engine runs, a stop watch was used to measure the time taken to consume $8 \mathrm{ml}$ of fuel and at the same time the exhaust emissions such as $\mathrm{NO}, \mathrm{HC}, \mathrm{CO}$ and $\mathrm{CO}_{2}$ were also measured using the exhaust gas analyser. The analyser displays the reading on the screen and the readings were recorded. In order to reduce experimental error, the test was repeated three times and the results average was taken. (iv) The same procedure was followed to repeat the experiments for 6, 8, 10 and $11 \mathrm{Nm}$. (v) For the second stage, the engine was set at constant torque $(4 \mathrm{Nm})$ with engine speed of $2000 \mathrm{rpm}$. Results were also obtained as in step (iii) and (iv) above. Same steps were repeated for 2200, 2400 and $2600 \mathrm{rpm}$. The same experimental procedure (i-v) was also used for B20, B20Bu5, $\mathrm{B} 20 \mathrm{Bu} 10$ and B20Bu15. The primary data obtained from the experiment were used in Microsoft Office Excel 2007 to develop the predictive equations using regression analysis. The exhaust gas emissions (NO, $\mathrm{CO}_{2}, \mathrm{CO}$ and $\mathrm{HC}$ ) were the dependent variables which are functions of torque $(\mathrm{T})$, speed $(\mathrm{N})$ and the blend ratio (B). Therefore, the predictive model equation is given by Rawlings et al., (1998) as shown in eqn (1) below.

$$
\left\{\begin{array}{l}
N O \\
H C \\
C O \\
C O_{2}
\end{array}\right\}=\varepsilon+a_{1} \mathrm{~T}+\mathrm{a}_{2} \mathrm{~N}+\mathrm{a}_{3} \mathrm{~B}
$$

Where $\mathrm{T}, \mathrm{N}$ and $\mathrm{B}$ are torque, speed and blend ratio respectively, while $\varepsilon, \mathrm{a}_{1}, \mathrm{a}_{2}$, and $\mathrm{a}_{3}$ are constants obtained from the regression analysis results.

\section{RESULTS AND DISCUSSION}

Exhaust emission results are presented in graphical form in the following figures. Fig. 1 shows the exhaust emission of $\mathrm{NO}$ at constant speed of $2600 \mathrm{rpm}$ and varying loads. It can be seen from fig. 1 that B20 blend shows the highest amount of $\mathrm{NO}$ emissions at all level of loads. This might be due to higher oxygen content in the blend compared with diesel which is in conformity with the result obtained by Dhamodaran et al., (2017); Aransiola et al., (2012); Mathiyazhagan et al., (2011). The addition of butanol to B20 significantly reduced the amount of $\mathrm{NO}$ emission and the reduction was more with increasing percentage of butanol in the blend. In spite of the higher oxygen content B20Bu15 has the lowest amount of $\mathrm{NO}$ emission (235 ppm) among all the fuel samples. This might be due to the temperature lowering effect of butanol which is caused by its high latent heat of vaporization.

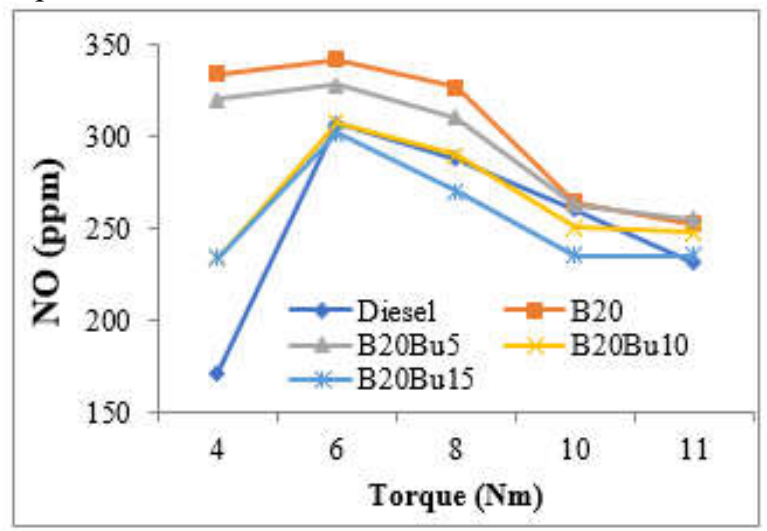

Fig 1: NO Emission vs Engine Load

Looking at fig. 5, there was a decreasing trend of NO emission for all tested fuels as the engine speed increased. This could be attributed to the short available time span of combustion as the engine speed becomes higher. B20 blend has NO emission of 303.8 ppm on average which is the highest compared with other tested fuels. 


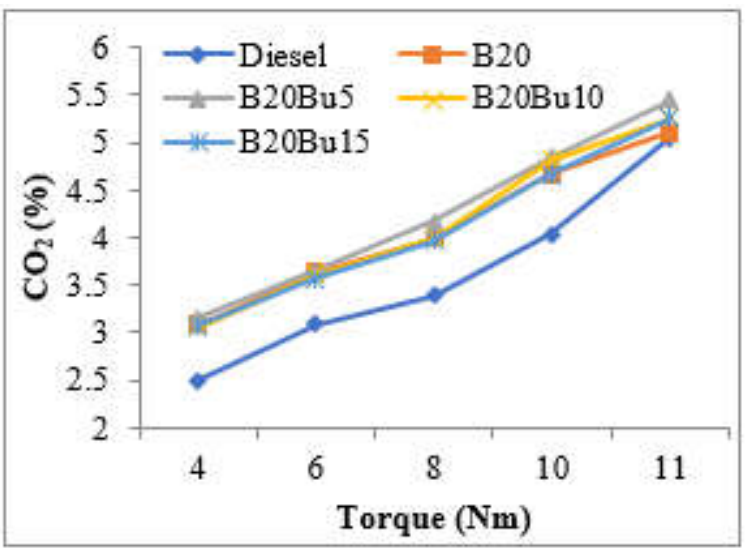

Fig 2: $\mathrm{CO}_{2}$ Emission vs Engine Load

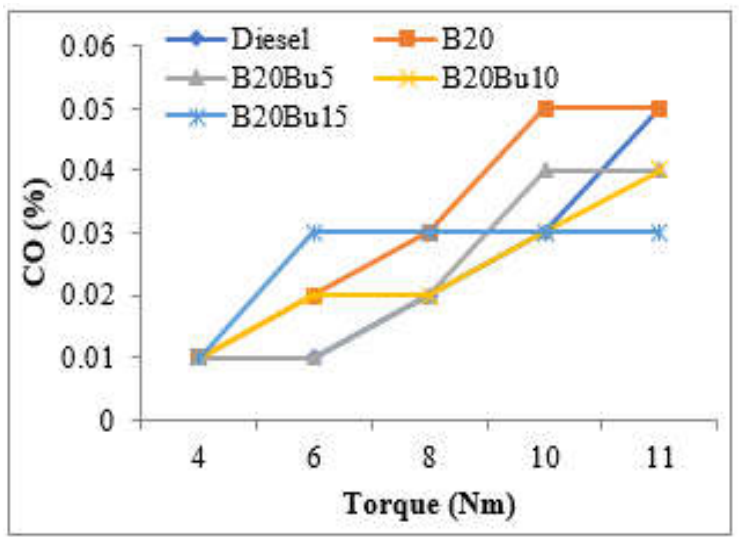

Fig 3: CO Emission vs Engine Load

However, the addition of butanol significantly reduced NO emission by about $16 \%$, and the reduction being higher as the percentage of butanol in the blend increased. Of all samples B20Bu15 has the lowest NO emission at all engine speeds except at $2600 \mathrm{rpm}$ where it is a little higher than pure diesel.

An increasing trend of $\mathrm{CO}_{2}$ emission was observed with increase in engine load for all samples as shown in fig. 2. This indicates that the test engine emits more $\mathrm{CO}_{2}$ at higher engine loads.

Diesel with $3.61 \%$ on an average has the lowest $\mathrm{CO}_{2}$ emission as compared to all blends. The result of this $\mathrm{CO}_{2}$ emission agreed with the result obtained by Lujaji et al., (2011). The oxygen in biodiesel and butanol eventually reacts with unburnt carbon atoms during combustion and increases $\mathrm{CO}_{2}$ formation. More amounts of $\mathrm{CO}_{2}$ and lower amount of $\mathrm{CO}$ in exhaust emission is an indication of complete combustion. $\mathrm{B} 20 \mathrm{Bu} 5$ has $\mathrm{CO}_{2}$ emission slightly higher than other blends. $\mathrm{CO}_{2}$ emission increased with increase in engine speed as shown in fig. 6. One can also observe that blends containing butanol emits higher amount of $\mathrm{CO}_{2}$ than $\mathrm{B} 20$ blend and diesel.

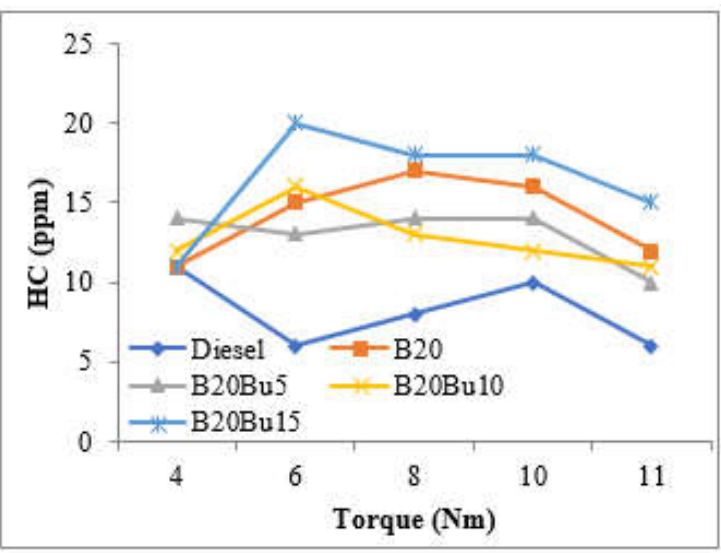

Fig 4: HC Emission vs Engine Load

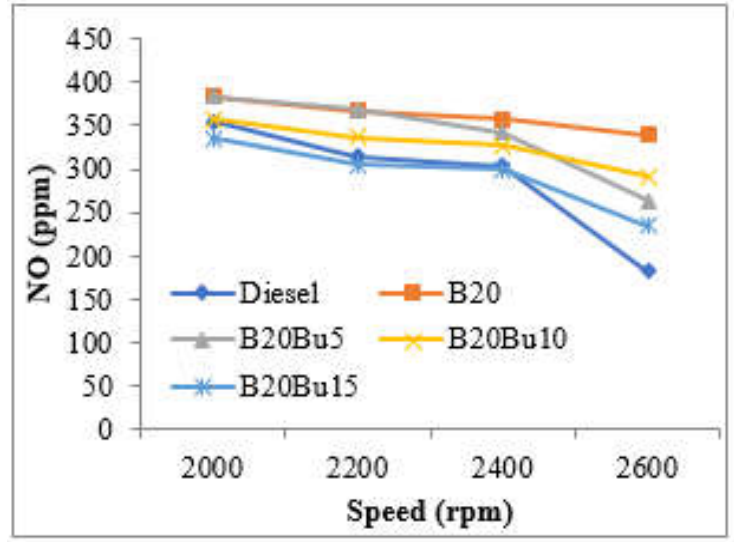

Fig 5: NO Emission vs Engine Speed

Further observation shows that between $2000 \mathrm{rpm}$ to $2400 \mathrm{rpm}$ the emission of $\mathrm{CO}_{2}$ for B20 and diesel fuel were almost the same but at $2600 \mathrm{rpm} \mathrm{B} 20$ becomes higher than diesel. However, $\mathrm{CO}_{2}$ emission decreased as the percentage of butanol in the blend increase. B20Bu 5 records $3.32 \%$ as the highest $\mathrm{CO}_{2}$ emission at engine speed of $2600 \mathrm{rpm}$. Increase in engine load resulted to increase in $\mathrm{CO}$ emission as seen in fig. 3. The main reason for this increase is because the airfuel ratio decreased with increase in load.

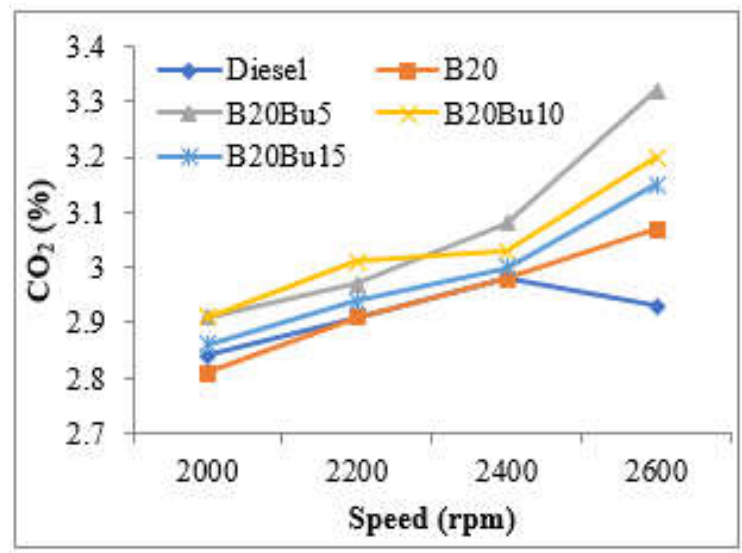

Fig 6: $\mathrm{CO}_{2}$ Emission vs Engine Speed 


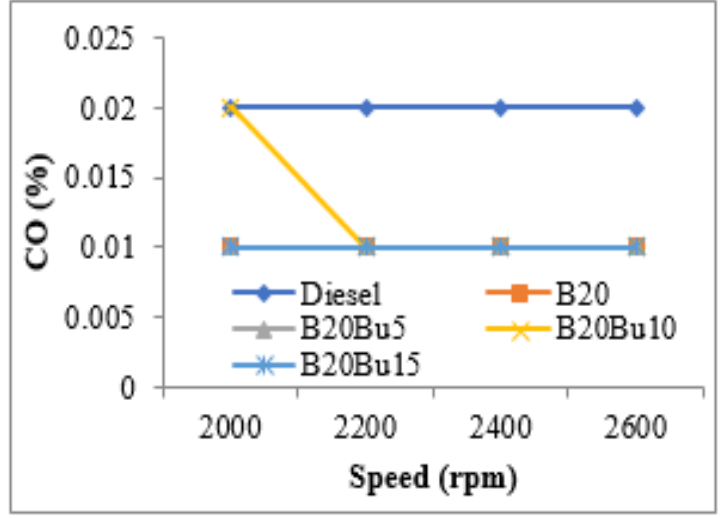

Fig 7: CO Emission vs Engine Speed

At higher load $(11 \mathrm{Nm})$ blends containing butanol greatly reduced $\mathrm{CO}$ emission, with $\mathrm{B} 20 \mathrm{Bu} 15$ having $0.03 \%$ being the minimum while $\mathrm{B} 20$ and diesel having $0.05 \%$ were maximal. At low load there was no positive effect when butanol was added to B20 blend. This might be due to low in-cylinder temperature and high latent heat of evaporation of butanol causing quenching effect over the piston and cylinder wall resulting in poor oxidation of $\mathrm{CO}$ to $\mathrm{CO}_{2}$. There was no significant difference in $\mathrm{CO}$ emission across engine speeds as shown in fig. 7. CO emission produced by B20 and blends containing butanol were lower than that of diesel fuel, with the reduction being as high as $50 \%$. A more complete combustion caused by the increased oxygen content in the flame coming from the oxygenated blends can be pointed out as the main reason for the reduction of $\mathrm{CO}$ emission.

$\mathrm{HC}$ emitted at different engine loads by all tested fuels are shown in fig. 4 which revealed that diesel fuel releases lower $\mathrm{HC}$ emission under the whole range of engine loads compared with all the fuel blends. $\mathrm{B} 20 \mathrm{Bu} 15$ blend records the maximum value of $\mathrm{HC}$ emission across all engine loads with $16.4 \mathrm{ppm}$ on average.

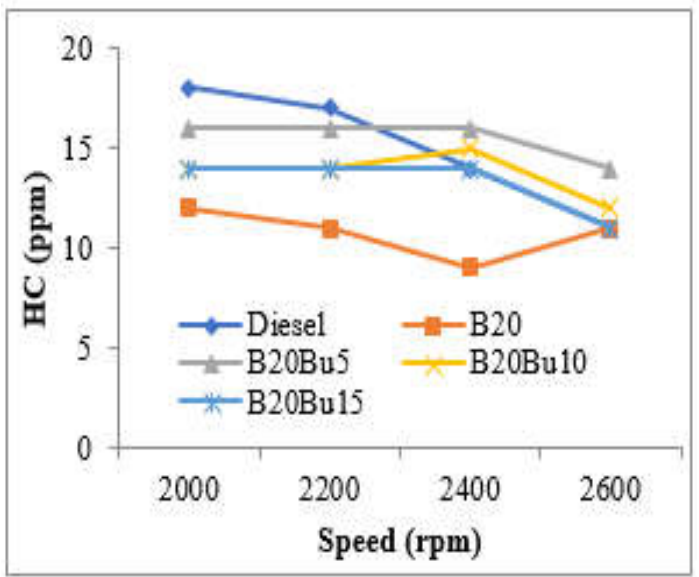

Fig 8: HC Emission vs Engine Speed
For B20Bu5 blend, $\mathrm{HC}$ emission was lower than that of B20 at loads between $6 \mathrm{Nm}$ to $11 \mathrm{Nm}$ while $\mathrm{B} 20 \mathrm{Bu} 10$ blend was lower than B20 at loads between $8 \mathrm{Nm}$ to $11 \mathrm{Nm}$. The emissions of HC decreased as the engine load increase was due to the more complete combustion achieved at higher engine load conditions. From fig. $8 \mathrm{HC}$ emissions was found to decrease with increasing engine speed. At low speed diesel fuel has the highest $\mathrm{HC}$ emission compared with other blends. B20 blend records the minimum $\mathrm{HC}$ emission across all the engine speed. Blends containing butanol were found to have $\mathrm{HC}$ emission of about $17 \%$ higher than B20 blend. Increased HC emission was also noted by Lujaji et al., (2011); Imtenan et al., (2015); Sharon et al., (2013) in their study with butanol-based blends. These might be attributed mainly to higher heat of vaporization of butanol, which makes it easier to evaporate and slip into the engine cylinder walls. This effect is more influential at low load conditions because the combustion temperature is itself lower than at high load.

The predictive equations for the exhaust emissions are shown in equations $2-5$.

$\mathrm{NO}=637.7191-6.44063 \mathrm{~T}-0.10919 \mathrm{~N}-3.89105 \mathrm{~B}$
$\mathrm{CO}_{2}=1.15329499+0.29018898 \mathrm{~T}+0.00029102 \mathrm{~N}+$ $0.00006943 \mathrm{~B}$

$\mathrm{CO}=0.00113887+0.00434302 \mathrm{~T}-0.0000028 \mathrm{~N}-$ $0.0001782 \mathrm{~B}$

$\mathrm{HC}=16.669647+0.1285259 \mathrm{~T}-0.0018557 \mathrm{~N}+$ $0.131111 \mathrm{~B}$

The adjusted $\mathrm{R}$ square values for $\mathrm{NO}, \mathrm{CO}_{2}, \mathrm{CO}$ and HC emissions were 0.758918, 0.97680284, 0.84560378 and 0.1318594 respectively. From these adjusted $\mathrm{R}$ square values, it could be observed that there is a very strong correlation between the exhaust emissions and the independent variables $(\mathrm{T}, \mathrm{N}$ and $\mathrm{B})$ with $\mathrm{NO}, \mathrm{CO}_{2}$ and $\mathrm{CO}$ having about $75.9 \%, 97.7 \%$ and $84.6 \%$ respectively. $\mathrm{HC}$ has about $13.2 \%$, which indicates a weak correlation between the $\mathrm{T}, \mathrm{N}$ and $\mathrm{B}$, and $\mathrm{HC}$ emission. This could be due to high p-values of $\mathrm{T}$ and $\mathrm{N}$ in the $\mathrm{HC}$ emission model which are greater than the $5 \%$ significance level.

Conclusions: Based on the experimental investigation, the following conclusions can be drawn. Addition of butanol to neem biodiesel-diesel blend can: 1 . effectively lower $\mathrm{CO}$ emission, 2 . reduce $\mathrm{NO}$ emission up to $16 \%$ as compared to $\mathrm{B} 20$, and 3. improves $\mathrm{CO}_{2}$ emission by $13.6 \%$ especially at high engine loads and also increase $\mathrm{HC}$ emission. The predictive model equations showed that there is strong correlation 
between the exhaust emissions and the independent variables (T, N and $\mathrm{B}$ ). Therefore, equations 2,3 and 4 could be used to predict the various emissions for a given fuel blend under a particular speed and torque.

\section{REFERENCES}

Aransiola, EF; Betiku, E; Ikhuomoregbe, DIO; Ojumu TV (2012). Production of Biodiesel from Crude Neem Oil Feedstock and its Emissions from Internal Combustion Engines. Afr. J. Biotechnol. 11(22): $6178-6186$.

Dhamodaran, G; Krishnan, R; Pochareddy, YK; Pyarelal, HM; Sivasubramanian, H; Ganeshram, AK (2017). A Comparative Study of Combustion, Emission and Performance Characteristics of Rice-bran, Neem and Cottonseed-Oil Biodiesels with Varying Degree of Unsaturation. Fuel, 187 : $296-305$.

Imtenan, S; Masjuki, HH; Varman, M; Fattah, IM; Sajjad, H; Arbab, MI (2015). Effect of n-Butanol and Diethyl Ether as Oxygenated Additives on Combustion-Emission Performance Characteristics of a Multiple Cylinder Diesel Engine Fuelled with Diesel-Jatropha Biodiesel Blends. Energy Conver. Manage. (94): 84 - 94.

Lapuerta, M; Armas, O; Garcia-contreras, R (2009). Effect of Ethanol on Blending Stability and Diesel Engine Emissions. Energy Fuels. 23: 4343 4354.
Lujaji, F; Kristof, L; Bereczky, A; Mbarawa, M (2011). Experimental Investigation of Fuel Properties, Engine Performance, Combustion and Emissions of Blends Containing Croton Oil, Butanol and Diesel on a C.I Engine. Fuel. 90: 505 $-510$.

Mathiyazhagan, M; Ganapathi, A; Jaganath, B; Renganayaki, N; Sasireka, N (2011). Production of Biodiesel from Non-Edible Plant Oils Having High FFA Content. Int. J. Chem. Environ. Engg. 2(2):119- 122.

Mehta, RN; Cakraborty, M; Mahanta, P; Parikh, PA (2010). Evaluaion of Fuel Properties of ButanolBiodiesel-Diesel Blends and Their Impact on Engine Performance and Emissions. Ind. Engg Chem. Res.49: 7660 - 7665.

Rawlings, JO Pantula, SG; Dickey, DA (1998). Applied Regresion Analysis: A Research Tool, Second Edition. Pp 76

Sharon, H; Ram, PJS; Fernando, KJ; Murali, S; Muthusamy, R (2013). Fueling a Stationary Direct Injection Diesel Engine with Diesel-Used Palm Oil-Butanol blends - An Experimental Study.Energy Conver. Manage. 73: 95 - 110

Zhang, Z; Balasubramanian, R (2014). Influence of Butanol Addition to Diesel- Biodiesel Blend on Engine Performance and Particulate Emissions of a Stationary Diesel Engine. Appl. Energy. 119: $530-536$. 